\title{
Civilization, National Culture And Ethical Work Climates: A Comparative Study Of CPA Firms In China And Taiwan
}

Gerald Venezia, Southern Taiwan University, Taiwan

Chiulien C. Venezia, Frostburg State University, USA

Yan Bao, Frostburg State University, USA

\begin{abstract}
The emergence of China as an economic power has prompted the question, what impact if any has globalization and market liberalization had on the ethical climate of organizations within China and its neighbor Taiwan? Cross-strait tensions have eased over the past few years due to closer economic integration. Although both countries differ in political, as well as organizational design, they share core cultural values embedded within civilization; Confucianism. This study attempts to understand how the correlation established between ethical climates and National culture by Parboteeah, Cullen, Victor, and Sakano are played out against the backdrop of a shared civilization. Will the ethical climates retain or deviate from the core civilization cultural values theorized by Samuel P. Huntington? To answer that question, we collected data from C.P.A. firms in China and Taiwan using the 36-item revised version of the Ethical Climate Questionnaire developed by John B. Cullen, Bart Victor (1988), and James W. Bronson (1993). The results indicated a significant difference in four areas: 1) principal-individual, 2) principle-cosmopolitan, 3) benevolence-individual, and 4) egoism-individual. When correlated with national culture and their core civilizational cultural value of Confucianism, deviations showed that Taiwan moved away from Confucian values by scoring higher in Egoism while retaining Confucianism with a more particularistic culture. China demonstrated a shift away from Confucian values by scoring higher in principle while retaining Confucian values through its score in benevolence.
\end{abstract}

Keywords: Ethical Work Climates; Principal; Benevolence; Egoism; Confucianism; National Culture; Ethical Decision-Making; China; Taiwan

\section{INTRODUCTION}

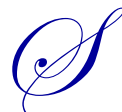

amuel P. Huntington (2003), in his seminal book, The Clash of Civilizations and the Remaking of World Order, describes civilization as the broadest cultural entity. He makes no distinction between the values, norms, and modes of thinking found in civilization or culture. A civilization may consist of numerous nations. While national culture may differentiate between one another at the local level, nations will maintain a consistency as a civilization (Huntington, 2003). Although Huntington refers to Chinese civilization as 'Sinic' - a broader term incorporating all of Southeast Asia, Korea, and Vietnam - in this study, we will use Confucian when referring to China and Taiwan. China and Taiwan may belong to the same civilization, but they exist as two sovereign nations. Taiwan may lack legal sovereignty, but does exhibit all other aspects of sovereignty (Krasner, 2001). For this study, Taiwan will be recognized as a separate nation as part of the same civilization as China. Parboteeah, Cullen, Victor, and Sakano (2005) understood the need to link national culture and ethical climates. Their research in comparing the US and Japan was premised on understanding how two different national cultures in this case, from two different civilizations - would impact ethical decisions, judgments, and rules in relation to social pressures and quality of relationships. Their study set out to provide an understanding how national cultures influence one another, how values and beliefs pervade ethical values of a profession, and, in the face of convergence of accounting standards, the cultural barriers that the profession will face. In our study, we recognize the efforts of 
Parboteeah et.al, but feel the need to enlarge the cultural affects to include the broadest cultural entity, civilization and its impact on national culture, and the organizational cultures imbued within the ethical work climates.

\section{LITERATURE REVIEW}

\section{Ethical Work Climates}

Ethical values are a set of guiding principles that encourage individuals in an organization to make decisions consistent with one's value system and the value system of the organization. They are expected to be ideally possessed by an employee. The Ethical Work Climate, developed by Bart Victor and John B. Cullen, (1987, 1988) and James W. Bronson (1993), states that organizations are responsible for any ethical or unethical actions that take place among their employees and likewise can initiate and implement ethical work climates. "Ethical climates are conceptualized as general and pervasive characteristics of organizations affecting a broad range of decisions" (Victor \& Cullen, 1988, p.101). The Ethical Climate Questionnaire is "simply an instrument to tap, through the perceptions of organizational participants, the ethical dimensions of organizational culture" (Victor \& Cullen, 1988, p.103). Therefore the participant becomes the 'type of observer' who views different kinds of behavior, whether in decision-making or their compliance in the organization's practices and procedures; "but not evaluating the perceived organizational expectations" (Cullen, Victor, \& Bronson, 1993, p. 671).

The Ethical Climate covers two dimensions of theoretical typology (Victor \& Cullen, 1988) - one is ethical criterion, which is used for the organization's decision-making, and the second - locus of analysis - refers to ethical decision-making.

The ethical criterion dimension covers three major classes of ethical theory (Victor \& Cullen, 1988) egoism, benevolence, and principle. Labeled as three major classes of a group or organizational concept, they do not follow an individual's perception or behavior. Egoism is defined as "the maximization of self-interest" (VanSandt, 2001 , p. 18). This means that a person believes in themselves, irrespective of opposed situations from society or opinions of other people to preserve dignity as an individual. The second dimension is benevolence where "people tend to be less cognizant of laws and rules and may also be amenable to arguments employing rules or principles" (Victor \& Cullen, 1988, p.105). This explains that an argument or discussion with a person who has lesser knowledge or ignorance of the law or rules might be ineffectual. Principle is the last dimension of ethical criterion where "people ... tend to be less sensitive to particular effects on others" (Victor \& Cullen, 1988, p. 105). This kind of situation usually happens when an honest and loyal worker becomes the enemy of another when breaking office policies in the work place. The honest and loyal employee takes some action by reporting the other employee to the management without any second thoughts, as long as they know that there is a violation of the policy.

Another part of the Ethical Work Climate is the locus of analysis dimension. This dimension represents the different sources of influences and motivation where a person might conceive its own perceptions on ethical or unethical issues. Victor \& Cullen (1988) stated that it "is a referent group identifying the source of moral reasoning used for applying ethical criteria to organizational decisions or the limits on what is considered the ethical analyses of organizational decisions" (p.105). Individual, local, and cosmopolitan are the categories comprising the second dimension. This locus of analysis demonstrates that ethical climate is an organizational concept (Victor \& Cullen, 1988).

Locus of individual "is external to the focal organization in the sense that the prevailing normative climate supports a referent for ethical reasoning located within the individual" (Victor \& Cullen, 1988, p.106). This locus explains that perceiving a kind of work climate within an organization can depend on how an individual perceives its environment from their own point of view. While individual locus focuses on oneself, the local locus "specifies sources of ethical reasoning within the organization, such as the work group" (Victor \& Cullen, 1988, p. 106). Victor \& Cullen (1988) also mentioned that for the local role incumbent, "the important reference group or sources of role definitions and expectations are contained within the social system" (p.106). This explains that within organizations, employees might perceive a positive or negative value depending on the type of group to which a person belongs. A group that places a high value on morale tends to influence an individual to perceive this kind of thinking; likewise, it is the same with work groups that place a low value on morale. 
A level which specifies organizational sources of ethical reasoning external to the focal organization, such as professional associations or a body of law (Victor \& Cullen, 1988), is what is called cosmopolitan. Developed law-based environments use this locus to perceive norms or morale which are acquired from other sources outside the organization.

Combining the two dimensions - ethical criterion and locus analysis - forms nine different criterions in order to describe the moral reasoning of an employee or individual.

The locus of the individual, when combined with ethical criterions, results in the following dimensions:

- $\quad$ egoism-individual (EI) results in self-interest

- $\quad$ benevolence-individual (BI) resulting in friendship

- $\quad$ principle-individual (PI) results in personal morality

Local locus, combined with the ethical criterions, creates:

- $\quad$ egoism-local (EL) resulting in company profits

- $\quad$ benevolence-local (BL) resulting in team interest

- $\quad$ principle-local (PL) explains a referent to company rules and procedures

For the last three sets of dimensions - the analytical combination of ethical criterion and locus of analysis the following are described: 1) egoism-cosmopolitan (EC) forms the dimension of efficiency while 2) benevolencecosmopolitan (BC) and 3) principle-cosmopolitan (PC) form the dimensions of social responsibility and laws and professional codes, respectively.

\section{Ethics and Accounting}

Ethics is a sensitive issue surrounding the practice of accounting that has taken on a more serious role the last few years. Nowadays, accountants face a test of their character by either following their normative and ethical point of view or simply 'take the easy option' (Lewis, 2006). The Code of Ethics in the accounting profession has evolved from eight core attributes (Integrity, Objectivity, Professional Competence, Due Care and Timeliness, Technical Standards, Professional Behavior, Confidentiality, and Independence, (Datu-Evangelista, 1997) to five principles - Integrity, Objectivity, Professional Competence and Due Care, Confidentiality, and Professional Behavior. These changes are encouraged as a standard measure for accounting practitioners around the world to protect them from different kinds of threats and to provide them with knowledge to handle uncomfortable and critical situations (Lewis, 2006).

The Ethical work climate (EWC) shares an interest with individuals and researchers from many different fields. Several authors had raised their own ethical work climate issues. Wittmer and Coursey (1996) stated, "Ethical climate is an extension of two related concepts - work climates and organizational culture shared perceptions of the ethical aspects of an organization's culture" (p.560). The two authors explained that these climates may mirror the culture of the organization but most likely will reflect the moral surface of the organization. A similar view from Vardi (2001) noted that ethical climates are "embedded in the organizational climate which is embedded in organizational culture" (p.333). This explains the possible reflection of ethical climates on local restraints and direction for behavioral actions of individuals. In contrast with Wittmer and Coursey's and Vardi's works, Parboteeah et al (2005) suggested that ethical cultural differences would reflect a greater difference in perceiving ethical climate values. These studies showed different approaches for studying the ethical climate in different industries and sectors of society.

\section{Ethical Work Climates and Globalization}

Parbooteeah et al. (2005) expanded their research by addressing cross-cultural ethics showing the relationship between the ethical work climates and national culture. Although their study compared the United States and Japan, they emphasized the need in a globalized world to understand the influence national culture has on 
local decision-making in assisting companies that do business across nations to build more ethical organizations (Parbooteeah et al. (2005). The accounting profession is converging toward a universal set of standards. The United States-based Financial Accounting Standards Board (FASB) and the International Accounting Standards Board (IASB) are working together to achieve convergence in a few years' time. As of April 2011, they have agreed upon five projects (pricewaterhousecoopers, 2011). China and the United Sates are in agreement that the world needs a single set of high-quality accounting standards (Norris, 2012). The European Union has adopted the use of the IFRS and 13 other countries around the world have - or are - also in the process of convergence with the IFRS (IFRS, 2012). Taiwan is moving toward convergence of GAAP and IFRS. China has developed its own accounting standards. The Chinese Accounting Standards (CAS) is somewhat converged with IFRS; however, it's not a direct translation of IFRS. The Ministry of Finance is working on eliminating the differences (pricewaterhousecoopers, 2011). The differences and effect of national culture on behavior within nations and organizations has been documented in the literature since Hofstede's seminal book Culture's Consequences. What we are attempting goes beyond those parameters to include the largest referent impact on cultural values - civilization. China and Taiwan share the same civilization - Confucianism. With the convergence of accounting practices imminent, the question of one size fits all arises; not only in the context of national culture, but civilizational culture as well. We will show that the organizational values grounded in the ethical work climates and their relationship with national culture are affected and driven by the core civilizational values found in the Confucian societies of China and Taiwan. The ethical implications are of importance since both China and Taiwan have developed their own code of ethics through their respective professional accounting associations.

\section{METHODOLOGY}

This study aims to discover the ethical work climate(s) perceived by Chinese and Taiwanese accountants. EWC dimensions will serve as the independent variables for this research study. The independent variables will determine whether the possible factors can show any significant effect on dependent variables, which are the accountants from CPA firms in China and in Taiwan.

\section{RESEARCH HYPOTHESES}

Cullen and Victor's (1988) definition of ethical work climate stated that it reflects employees' collective perceptions of ethical events, ethical practices, and procedures. The ethical climate covers two-dimensional areas: 1) Locus of analysis (which covers the individual, local, and cosmopolitan) deals with the perceived values from different sources of influence and motivation and 2) ethical criterion (principle, benevolence, and egoism) deals with the perceived values from a group or organization. From there, ethical climate produces nine ethical climate dimensions, such as self-interest, friendship, personal morality, company profit, team interest, company rules and procedures, efficiency, social responsibility, and the laws and professional codes that represent the values that individuals might conceive within their organization. Using these theoretical aspects of ethical climate, this research study wants to know what will be the ethical work climate values that Chinese and Taiwanese accountants perceive from their organization or institution. This will provide the evidence to compare the climates to national culture in relation to the core civilization values, thus determining the impact organizational and/or civilization has on the ethical work climates.

This study will examine whether there is a significant difference between accountants in China and Taiwan on the perceived ethical work climate value(s) from their organization or institution.

$\mathbf{H}_{1}$ : $\quad$ Chinese and Taiwanese accountants demonstrate no significant difference on the perceived principal ethical work climates.

$\mathbf{H}_{2}$ : Chinese and Taiwanese accountants demonstrate no significant difference on the perceived benevolent ethical work climates.

$\mathbf{H}_{3}$ : $\quad$ Chinese and Taiwanese accountants demonstrate no significant difference on the perceived egoism ethical work climates. 


\section{Research Instrument}

The research instrument used for this study was the Ethical Climate Questionnaire (ECQ) developed by John Cullen, Bart Victor (1988), and James W. Bronson (1993). The questionnaire is composed of 36 Likert-scale items representing the nine dimensional values of ethical work climate, along with personal information such as the respondents' gender, age, civil status, and years of job experience. The 36 items of ECQ are answerable on an interval scale ranging from 1 to -5 (completely false to completely true). The Chinese version of the survey questionnaire, along with demographic information, was distributed to Chinese and Taiwanese accountants.

\section{Data Collection}

Research samples are basically composed of Chinese and Taiwanese CPAs who work in accounting firms in China and Taiwan. As shown in Table 1, a total of 383 samples were collected, in which 272 were collected from CPA firms in China and 111 from CPA firms in Taiwan. For gender analysis, the whole group is divided into Male (145) and Female (238).

Table 1: Sample Description

\begin{tabular}{|l|l|c|}
\hline & & Number of Observations \\
\hline \multirow{3}{*}{ Country } & China & 272 \\
\cline { 2 - 3 } & Taiwan & 111 \\
\cline { 2 - 3 } & Total & 383 \\
\hline
\end{tabular}

\section{RESULTS}

The perception differences between CPAs from China and Taiwan, with regard to nine ECQ dimensions, are examined using T-test. The results are reported in Table 2. The significant level is associated with $95 \%$ confidence interval levels.

Table 2 indicates that principle-local, benevolence-local, benevolence-cosmopolitan, egoism-local, and egoism-cosmopolitan show no significant differences between Chinese and Taiwanese accountants, while principleindividual, principle-cosmopolitan, benevolence-individual, and egoism-individual show significant differences between the two groups. Therefore, all three hypotheses are partially supported.

Table 2: Independent Sample T-test on ECQ Perceptions - China vs. Taiwan

\begin{tabular}{|l|c|c|c|}
\hline \multirow{2}{*}{ ECQ Dimensions } & \multicolumn{2}{|c|}{ M E A N } & \multirow{2}{*}{ Significance } \\
\cline { 2 - 3 } & China & Taiwan & .000 \\
\hline Principle-individual & 3.3272 & 3.2162 & .449 \\
\hline Principle-local & 3.9807 & 3.6081 & .012 \\
\hline Principle-cosmopolitan & 4.0919 & 3.8266 & .018 \\
\hline Benevolence-individual & 3.3014 & 3.129 & .120 \\
\hline Benevolence-local & 3.5049 & 2.9487 & .542 \\
\hline Benevolence-cosmopolitan & 3.9648 & 3.4503 & .001 \\
\hline Egoism-individual & 3.0199 & 3.1964 & .114 \\
\hline Egoism-local & 3.5985 & 3.4306 & .481 \\
\hline Egoism-cosmopolitan & 3.8327 & 3.4572 & \\
\hline
\end{tabular}

Although China and Taiwan developed separate political and economic systems over time, they have shared the same core civilizational cultural value - Confucianism. Parboteeah, Cullen, Victor, and Sakano (2005) compared national culture and ethical climates suggesting a relationship between Hofstede's cultural indices and Trompenaars' cultural values. Egoism was associated with individualism as benevolence with collectivism. The work climate principle finds a correlation with Trompenaars particularism, which rests upon situational relationships that are consistent with Confucianism. Its opposite - universalism (the following of rules and laws) - is more synonymous with countries similar to the United States (Smith, Peterson, \& Thomas, 2008).

Using the core civilizational cultural value of Confucianism as our basis to interpret the results; we will analyze where China and Taiwan agree or deviate from the core civilizational cultural value and its impact on 
ethical decision-making. In five of the nine work climates, there is no significant difference. Where we found a difference was with Principle and Benevolence in China and Egoism in Taiwan.

Taiwan scored higher in Egoism-individual. Egoistic climates are associated with cultures that are high in individualism. Moran, Harris, \& Moran (2007) noted that Taiwanese are inclined to be individualistic. Taiwan's move toward individualism is further supported through Venezia's (2007) collection of data using Hofstede's cultural values survey. Egoistic ethical climates encourage personal gain. The results indicate a shift in Taiwan away from Confucian values most associated with collectivism. On the other hand, China has retained its affiliation with collectivism with a higher score in benevolence. In a benevolent climate, the concern of the decision-maker is guided by subverting the individual need at the expense of collective gains (Parboteeah, Cullen, Victor \& Sakano, 2005). Surprising though, by scoring higher in principle, China demonstrates a shift away from Confucian values observed through Trompenaars definition of universalism and particularism. A principal ethical climate being associated with universalism is mostly associated with countries like the United States, where ethical decisions are made through the interpretation of rule, laws, and standards (Parboteeah et.al., 2005). Particularlistic climates are consistent with Confucianism where emphasis on building relationships (guanxi) factor in decision-making. Taiwan exhibits a more particularistic climate than China.

\section{LIMITATION OF THIS STUDY}

Results from this study need to be interpreted with caution. The data were collected from small scale firms in northern China and from four CPA firms in Taiwan due to the difficulty of obtaining survey feedback. The relatively small sample sizes may not be able to represent the whole population of accountants in China and Taiwan. Therefore, the perception of the ethical work climates obtained from this analysis may not be able to be generalized to the entire country/region. Secondly, there is no research that has expanded beyond the analysis of ethical work climate and national culture to include civilization.

\section{CONCLUSION}

In conclusion, we have shown that the core civilizational cultural value of Confucianism still exhibits its influence on the ethical work climates in both China and Taiwan but deviates with two notable exceptions principle and benevolence in China and egoism in Taiwan. Looking at the overall individual scores, China tends to demonstrate a stronger affiliation with Confucian values than Taiwan.

\section{AUTHOR INFORMATION}

Dr. Gerald Venezia is an assistant professor of International Business at Southern Taiwan University, Taiwan. He earned his DPA from Nova Southeastern University in Fort Lauderdale, FL. He teaches Business Ethics, Organizational Behavior and Multi-lateral Trading. He has published a number of research articles in international journals. E-mail: gvenezia@mail.stut.edu.tw

Dr. Chiulien C. Venezia, CPA is an assistant professor of Accounting at Frostburg State University, Maryland. She earned her DBA in Accounting from Nova Southeastern University in Fort Lauderdale and MS in Accounting from University of Missouri at Kansas City. Her main teaching is Managerial Accounting and Cost Accounting. She has published a number of research articles in international journals. E-mail: cvenezia @ frostburg.edu (Corresponding author)

Dr. Yan Bao, CPA is an associate professor of Accounting at Frostburg State University, Maryland. She earned her $\mathrm{PhD}$ in Business Administration from Kent State University. She has published a number of research papers in international journals. E-mail: ybao@frostburg.edu 


\section{REFERENCES}

1. Cullen, J.B., Victor, B., \& Bronson, J.W. (1993). The ethical climate questionnaire: an assessment of its development and validity. Psychological Reports, 73, 667-674

2. Datu-Evangelista, R. (1997). Ethics: the soul of a globalized practice of accountancy. Accountants' Journal, 50 (3\&4), 30-38.

3. Huntington, S.P. (2003). The Clash of Civilizations and the Remaking of World Order. Simon \& Schuster Paperbacks. New York.

4. IFRS (2012). Retrieved from http://www.ifrs.org/Use+around+the+world.htm. on June 28, 2012.

5. Krasner, S.D. (2001). Problematic Sovereignty. Columbia University Press. New York.

6. Lewis, T. (2006). Comment inside the moral maze. Public Finance; Accounting Tax \& Periodicals, Jun30Jul 6, 2006, 17.

7. Moran, R.T., Harris, P.R., \& Moran, S.V. (2007). Managing Cultural Differences: Global Leadership Strategies for the $21^{\text {st }}$ Century. Elesevier Inc., Oxford, UK.

8. Norris, Floyd. (2012). The Case for Global Accounting, May 10, 2012. New York Times, Retrieved from http://www.nytimes.com /2012/05/11/business/The-case-for-global-accounting on 6/13/2012.

9. $\quad$ Parboteeah, K.P., Cullen, J.B., Victor, B., \& Sakano, T. (2005). National culture and ethical climates: a comparison of U.S. and Japanese accounting firms. Management International Review, 45 (4), 459-481.

10. Pricewaterhousecoopers, (2011). Progress report on IASB-FASB convergence work, 21 April 2011. Retrieved from http://www.pwc.com on 6/14/2012.

11. Smith, P.B., Peterson, M.F., \& Thomas, D.C. (2008). The Handbook of Cross-Cultural Management Research. Sage Publications, Inc., CA.

12. VanSandt, C.V. (2001). An examination of the relationship between ethical work climate and moral awareness. Unpublished doctoral dissertation, Virginia Polytechnic Institute and State University, USA.

13. Vardi, Y. (2001). The effects of organizational and ethical climates on misconduct of work. Journal of Business Ethics, 29 (4), 325-337.

14. Venezia, G. (2007). Unpublished data collected from 2004-2007 using Hofstede's Cultural Values Survey.

15. Victor, C. \& Cullen, J.B. (1987). A Theroy and Measure of Ethical Climate in Organizations. Research in Social Performance \& Policy, 9 , 1987, 51-72.

16. Victor, C. \& Cullen, J.B. (1988). The organizational bases of ethical work climates. Administrative Science Quarterly, 33 (1), 101-125. 


\section{NOTES}

